\title{
Bacterial LuxR solos have evolved to respond to different molecules including signals from plants
}

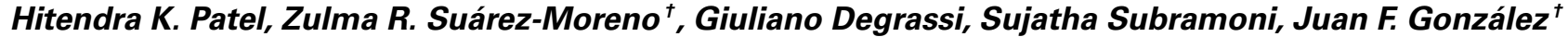 \\ and Vittorio Venturi*
}

International Centre for Genetic Engineering and Biotechnology, Trieste, Italy

\section{Edited by:}

Anton Dr. Hartmann, Helmholtz

Zentrum München, German Research

Center for Environmental Health,

Germany

\section{Reviewed by:}

Choong-Min Ryu, Korea Research

Institute of Bioscience and

Biotechnology, South Korea

Andrea Genre, University of Turin, Italy

\section{*Correspondence:}

Vittorio Venturi, International Centre

for Genetic Engineering and

Biotechnology, Padriciano 99, 34149

Trieste, Italy

e-mail: venturi@icgeb.org

\section{${ }^{\dagger}$ Present address:}

Zulma R. Suárez-Moreno, Biocultivos S. A. Instituto de Biotecnología,

Universidad Nacional de Colombia,

Ciudad Universitaria, Cra. $30 \mathrm{~Np}$.

45-03, Bogotá DC, Colombia; Juan F.

González, Department of Microbial

Infection and Immunity, The Ohio

State University, Columbus OH, USA
A future challenge will be understanding the extensive communication that most likely takes place in bacterial interspecies and interkingdom signaling between plants and bacteria. A major bacterial inter-cellular signaling system in Gram-negative bacteria is Luxl/R quorum sensing (OS) based on the production (via the Luxl-family proteins) and detection (via the LuxR-family proteins) of $\mathrm{N}$-acyl homoserine lactones (AHLs) signaling molecules. LuxR proteins which have the same modular structure of OS LuxRs but are devoid of a cognate Luxl AHL synthase are called solos. LuxR solos have been shown to be responsible to respond to exogenous AHLs produced by neighboring cells as well endogenously produced AHLs. It is now also evident that some LuxR proteins have evolved from the ability to binding AHLs and respond to other molecules/signals. For example, recent research has shown that a sub-family of LuxR solos responds to small molecules produced by plants. This indicates the presence of a uni-directional interkingdom signaling system occurring from plants to bacteria. In addition LuxR solos have now been also implicated to respond to endogenously produced signals which are not AHLs. In this Mini Review article we will discuss current trends and implications of the role of LuxR solos in bacterial responses to other signals using proteins related to AHL QS systems.

Keywords: quorum sensing, $\boldsymbol{N}$-acyl homoserine lactones, interkingdom signaling, LuxR solos, plant signals

\section{BACTERIAL QUORUM SENSING SYSTEMS AND LUXR SOLOS}

The most common bacterial quorum sensing (QS) system in Gram-negative bacteria occurs via $N$-acyl homoserine lactones (AHLs). A canonical QS system consists of a LuxI-family synthase responsible for synthesizing the AHL signal which then interacts at quorum concentrations with the cognate LuxR-family transcription factors affecting gene expression (Fuqua et al., 2001). Importantly, AHLs vary in their structure having different acyl chain lengths (from 4 to 20 carbons) with variation in the oxidation state at position C3 on the acyl chain (being a methylene, or a ketone, or can be hydroxylated).

Extensive research on bacterial AHL QS revealed that many plant associated bacteria (PAB) employ QS for the regulation of virulence associated functions of phyto-pathogens and of beneficial traits in plant-growth-promoting bacteria (Cha et al., 1998; Gonzalez and Marketon, 2003; Von Bodman et al., 2003; Danhorn and Fuqua, 2007). Researchers are also currently studying AHLs as interkingdom signals being perceived by plants. In fact, several studies are indicating that plants respond to bacterial AHLs regulating plant gene expression affecting important phenotypes (Mae et al., 2001; Mathesius et al., 2003; Toth et al., 2004; Schuhegger et al., 2006; You etal., 2006; von Rad et al., 2008; Schikora et al., 2011; Schenk et al., 2012). Importantly, plants also interfere with bacterial QS systems by producing low molecular weight compounds which mimic QS signals acting as agonists or antagonists to bacterial AHL QS systems (Teplitski et al., 2000; Manefield et al., 2002; Gao et al., 2003; Bauer and Mathesius, 2004; Teplitski et al., 2004; Keshavan et al., 2005; Degrassi et al., 2007). QS systems in $\mathrm{PAB}$ therefore appear to be influenced by plant molecules but also affect plant gene expression via AHLs.

Quorum sensing LuxR-family proteins are transcriptional regulators that bind AHLs being approximately 250 amino acids long and consisting of two domains separated by a short linker region; an autoinducer-binding domain is located in the $N$-terminal region (Shadel et al., 1990; Slock et al., 1990) and a DNA-binding helix-turn-helix (HTH) domain is positioned at the C-terminal region (Choi and Greenberg, 1991, 1992; Fuqua and Winans, 1994). LuxR-type proteins regulate transcription by binding to DNA in gene promoter regions at a conserved site called a lux box (Devine et al., 1989; Stevens and Greenberg, 1997). QS LuxRs display surprisingly low homologies (18-25\%); 95\% however, share nine highly conserved amino acid residues (Whitehead et al., 2001; Zhang et al., 2002). Six of these are hydrophobic or aromatic and form the cavity of the AHL-binding domain and the remaining three are in the HTH domain (Fuqua et al., 1996). AHL QS systems consist of the luxI/R genes, which are almost always located genetically adjacent to each other. Sequencing bacterial genomes showed that proteobacteria possess a family of proteins highly 
similar to QS LuxRs which do not possess a cognate LuxI protein associated with them; these have been called orphans and solos (Fuqua, 2006; Subramoni and Venturi, 2009).

LuxR solos consist of the same modular structure having an AHL binding domain in the $N$-terminus and a DNA binding $\mathrm{HTH}$ at the C-terminus. Some have been shown to expand the regulatory targets of the canonical complete AHL QS systems by responding to endogenous or exogenous AHLs. In the latter case, they regulate target genes by "eaves-dropping" on exogenously provided AHL signals produced by neighboring bacteria (Ahmer, 2004). Two well studied such LuxR solos are QscR from $P$. aeruginosa which responds to endogenously produced AHLs (Chugani et al., 2001; Lequette et al., 2006) and SdiA of Salmonella enterica and Escherichia coli which eavesdrop on AHLs produced by neighboring bacteria (Ahmer et al., 1998; Michael et al., 2001; Ahmer, 2004; Yao et al., 2006). A sub-family of these LuxR solos only found in PAB have lost the capacity to bind AHLs and instead evolved the ability to respond to low-molecular weight plant compounds. This uni-directional interkingdom signaling circuit has therefore evolved from canonical AHL QS systems where the LuxR protein no longer responds to endogenously produced AHLs, but to plant signals (Gonzalez and Venturi, 2013; Venturi and Fuqua, 2013). In addition LuxR solos have also recently been shown to respond to endogenous signals which are not AHLs again highlighting the evolution away from responding to AHLs of these proteins.

In this mini-review we wish to discuss/review that LuxR solos are evolving away from binding AHLs and can belong to an interkingdom circuit between $\mathrm{PAB}$ and plants. In addition very recent results also indicate that LuxR solos have evolved to be part of QS systems that produce and respond to molecules which are not AHLs. From the sequencing of proteobacterial genomes it is evident that LuxR solos are common and widespread meaning that many different forms of signaling could have evolved from the canonical AHL QS systems.

\section{OS LUXR-FAMILY PROTEINS AND INTERKINGDOM SIGNALING WITH PLANTS}

A LuxR solo sub-family has been recently discovered which are only found in PAB that do not bind AHLs but to plant produced compounds (Gonzalez and Venturi, 2013; Venturi and Fuqua, 2013). These LuxRs are very closely associated to QS LuxRs differing in the conservation of one or two of the six highly conserved amino acids in the AHL-binding domain. An AHL QS system widely distributed among PAB has therefore evolved away from being a bacterial intercellular signaling pathway and is now part of an interkingdom circuit between bacteria and plants. Compared to canonical QS LuxRs, this solo sub-family lacks some conservation in the AHL-binding domain which most probably allows them to bind to plant low molecular weight compounds rather than AHLs (Ferluga and Venturi, 2009).

Five members of this subfamily have been studied and these are XccR of Xanthomonas campestris pv. campestris (Xcc), OryR of Xanthomonas oryzae pv. oryzae (Xoo), PsoR of Pseduomonas fluorescens, XagR of Xanthomonas axonopodis pv. glycines (Xag) and NesR of Sinorhizobium meliloti (Ferluga et al., 2007; Zhang et al., 2007; Ferluga and Venturi, 2009; Patankar and Gonzalez, 2009; Subramoni et al., 2011; Chatnaparat et al., 2012). OryR of the rice vascular pathogen $X o o$ is involved in virulence, it responds to plant signals and activates the expression of the neighboring pip and of motility genes (Ferluga et al., 2007; Ferluga and Venturi, 2009; Gonzalez et al., 2013). XccR of the crucifer pathogen Xcc also responds to a yet unidentified plant compound and regulates the neighboring pip gene (Zhang et al., 2007). XagR of the soybean pathogen Xag which causes bacterial leaf pustule on soybean (Glycine $\max$ ) is also involved in virulence (Chatnaparat et al., 2012). Like XccR in Xcc, XagR in Xag also activates pip transcription in planta and temporal studies have indicated that pip transcription increases gradually after infection, reaching greatest activity after $72 \mathrm{~h}$, before slowly decreasing. This observation could be due to a plant compound(s) which are produced by the plant in response to pathogen attack by Xag. Interestingly, a similar observation has been made with pip regulation by OryR in Xoo (Ferluga and Venturi, 2009). XagR is also involved in the negative regulation of adhesion via yapH in response to plant compound(s) facilitating the spread of the pathogen in the plant (Chatnaparat et al., 2012). Two of these LuxR-type proteins have been studied in plant-beneficial bacteria, namely PsoR of P. fluorescens and NesR of S. meliloti (Patankar and Gonzalez, 2009; Subramoni et al., 2011). PsoR responds to plant compounds of several plant species and plays a role in biocontrol of rhizospheric $P$. fluorescens by controlling transcriptional regulation in response to plant compound(s), of various anti-microbial-related genes (Subramoni et al., 2011). NesR of S. meliloti has been associated with survival under stress and utilization of various carbon sources (Patankar and Gonzalez, 2009).

Importantly, homologs of OryR/XccR/XagR are also present in the major genera of PAB including Dickeya, Xanthomonas, Agrobacterium, Pseudomonas, Rhodospirillum, Citreicella, Rhizobium, Sinorhizobium (Gonzalez and Venturi, 2013). Homologs are only present in $\mathrm{PAB}$ meaning that this sub-family evolved to respond to plant compounds. This sub-family therefore represents a widespread uni-directional interkingdom signaling between plants and bacteria. Interestingly all genes of this $\operatorname{lu} x R$ family have an adjacent pip gene (in some cases two, one on each side of the gene) questioning the possible role of pip in this circuit.

\section{LUXR SOLOS AS PART OF NOVEL OS SYSTEMS}

A very recent finding in the insect pathogen Photorhabdus luminiscens has opened up new directions toward LuxR responsiveness to bacterial endogenous molecules that are not AHLs. The P. luminiscens genome was found to possess two LuxR solos; one was highly homologous to SdiA of S. enterica and was therefore predicted to bind AHLs whereas the other LuxR solo, designated PluR, was found to respond to a new class of endogenously produced signaling molecules that are not AHLs. PluR was found detecting $\alpha$-pyrones which are endogenously produced by a ketosynthase called PpyS. PluR is therefore part of a novel QS system and PpyS/PluR represents a new type of cell-cell communication circuit shown to regulate cell-clumping in P. luminiscens (Brachmann etal., 2013). This is another example where LuxR solos have evolved away from the ability to bind to AHLs; it is therefore likely that since many LuxR solos are present in proteobacteria, several will most probably bind and respond to different signal molecules. Interestingly, the majority of PAB have multiple LuxR solos; some 


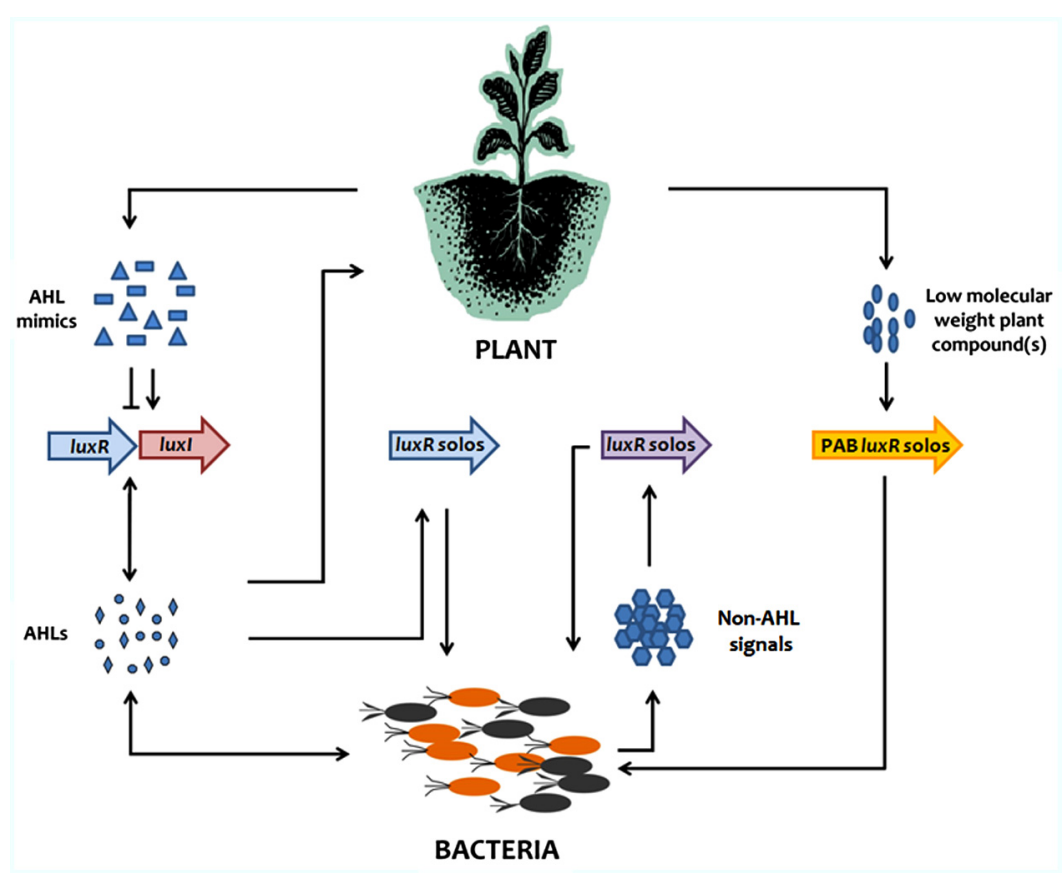

FIGURE 1 | Summary of current mode of action of AHL OS and of LuxR solos in signaling between plants and bacteria.

of them being related to AHL binding, others binding to plant compounds but some will most probably be involved in binding other signaling molecules, either endogenous or exogenous, which have not yet been identified.

\section{PERSPECTIVES}

LuxR solos which are closely related to QS AHL LuxRs are widespread among proteobacteria. Recent studies have evidenced that LuxR solos have evolved away from responding to AHLs and bind to other signals (Figure 1). A sub-family of PAB LuxR solos are not involved in a QS response but rather respond to plant signals providing information to the bacterium of its arrival/entry in the plant for both pathogenic and beneficial species. Obviously, the outcome of this interkingdom response varies between pathogenic and beneficial bacteria as revealed for example with regulon studies of OryR in Xoo and PsoR in P. fluorescens. The major step now in better understanding this system is to identify the structure of the plant molecule(s) to which this LuxR-family responds to. This will be a major challenge as plants produce a very large number of low molecular weight secondary metabolites. It is tempting to think that the molecules will be structurally close to AHLs; however, as AHLs do not bind these LuxRs and do not interfere/compete with the plant response it could indicate that they are structurally unrelated. It is possible that different LuxRs of this subfamily bind/respond to different but related plants signals since so many different bacteria possess them interacting with many different plants. We cannot exclude however, that the plant signal is the same being a common compound present in many plants. Recently, the discovery that a LuxR solo responds to a different endogenous signal that is not an AHL opens the way to LuxR solos being part of other types of QS systems. In future work, we need therefore to consider that many LuxR solos may have evolved the ability to respond to a wide variety of signals.

\section{ACKNOWLEDGMENTS}

Hitendra K. Patel is beneficiary of an ICGEB fellowship. Vittorio Venturi's laboratory is funded by Progetto AGER RISINNOVA and by ICGEB core funding.

\section{REFERENCES}

Ahmer, B. M. (2004). Cell-to-cell signalling in Escherichia coli and Salmonella enterica. Mol. Microbiol. 52, 933-945. doi: 10.1111/j.1365-2958.2004.04054.x

Ahmer, B. M., Van Reeuwijk, J., Timmers, C. D., Valentine, P. J., and Heffron, F. (1998). Salmonella typhimurium encodes an SdiA homolog, a putative quorum sensor of the LuxR family, that regulates genes on the virulence plasmid. $J$. Bacteriol. 180, 1185-1193.

Bauer, W. D., and Mathesius, U. (2004). Plant responses to bacterial quorum sensing signals. Curr. Opin. Plant Biol. 7, 429-433. doi: 10.1016/j.pbi.2004.05.008

Brachmann, A. O., Brameyer, S., Kresovic, D., Hitkova, I., Kopp, Y., Manske, C., et al. (2013). Pyrones as bacterial signaling molecules. Nat. Chem. Biol. 9, 573-578. doi: 10.1038/nchembio.1295

Cha, C., Gao, P., Chen, Y. C., Shaw, P. D., and Farrand, S. K. (1998). Production of acyl-homoserine lactone quorum-sensing signals by gram-negative plant-associated bacteria. Mol. Plant Microbe Interact. 11, 1119-1129. doi: 10.1094/MPMI.1998.11.11.1119

Chatnaparat, T., Prathuangwong, S., Ionescu, M., and Lindow, S. E. (2012). XagR, a LuxR homolog, contributes to the virulence of Xanthomonas axonopodis pv. glycines to Soybean. Mol. Plant Microbe Interact. 25, 1104-1117. doi: 10.1094/MPMI-01-12-0008-R

Choi, S. H., and Greenberg, E. P. (1991). The C-terminal region of the Vibrio fischeri LuxR protein contains an inducer-independent lux gene activating domain. Proc. Natl. Acad. Sci. U.S.A. 88, 11115-11119. doi: 10.1073/pnas.88.24.11115

Choi, S. H., and Greenberg, E. P. (1992). Genetic dissection of DNA binding and luminescence gene activation by the Vibrio fischeri LuxR protein. J. Bacteriol. 174, 4064-4069. 
Chugani, S. A., Whiteley, M., Lee, K. M., D'argenio, D., Manoil, C., and Greenberg, E. P. (2001). QscR, a modulator of quorum-sensing signal synthesis and virulence in Pseudomonas aeruginosa. Proc. Natl. Acad. Sci. U.S.A. 98, 2752-2757. doi: 10.1073/pnas.051624298

Danhorn, T., and Fuqua, C. (2007). Biofilm formation by plant-associated bacteria. Annu. Rev. Microbiol. 61, 401-422. doi: 10.1146/annurev.micro.61.080706.093316

Degrassi, G., Devescovi, G., Solis, R., Steindler, L., and Venturi, V. (2007). Oryza sativa rice plants contain molecules which activate different quorum sensing $\mathrm{N}$-acyl homoserine lactone biosensors and are sensitive to the specific AiiA lactonase. FEMS Microbiol. Lett. 269, 213-220. doi: 10.1111/j.15746968.2006.00624.x

Devine, J. H., Shadel, G. S., and Baldwin, T. O. (1989). Identification of the operator of the lux regulon from the Vibrio fischeri strain ATCC7744. Proc. Natl. Acad. Sci. U.S.A. 86, 5688-5692. doi: 10.1073/pnas.86.15.5688

Ferluga, S., Bigirimana, J., Hofte, M., and Venturi, V. (2007). A LuxR homologue of Xanthomonas oryzae pv. oryzae is required for optimal rice virulence. Mol. Plant Pathol. 8, 529-538. doi: 10.1111/j.1364-3703.2007.00415.x

Ferluga, S., and Venturi, V. (2009). OryR is a LuxR-family protein involved in interkingdom signaling between pathogenic Xanthomonas oryzae pv. oryzae and rice. J. Bacteriol. 191, 890-897. doi: 10.1128/JB.01507-08

Fuqua, C. (2006). The QscR quorum-sensing regulon of Pseudomonas aeruginosa: an orphan claims its identity. J. Bacteriol. 188, 3169-3171. doi: 10.1128/JB.188.9.3169-3171.2006

Fuqua, C., Parsek, M. R., and Greenberg, E. P. (2001). Regulation of gene expression by cell-to-cell communication: acyl-homoserine lactone quorum sensing. Annu. Rev. Genet. 35, 439-468. doi: 10.1146/annurev.genet.35.102401.090913

Fuqua, C., Winans, S. C., and Greenberg, E. P. (1996). Census and consensus in bacterial ecosystems: the LuxR-LuxI family of quorum-sensing transcriptional regulators. Annu. Rev. Microbiol. 50, 727-751. doi: 10.1146/annurev.micro.50. 1.727

Fuqua, W. C., and Winans, S. C. (1994). A LuxR-LuxI type regulatory system activates Agrobacterium Ti plasmid conjugal transfer in the presence of a plant tumor metabolite. J. Bacteriol. 176, 2796-2806.

Gao, M., Teplitski, M., Robinson, J. B., and Bauer, W. D. (2003). Production of substances by Medicago truncatula that affect bacterial quorum sensing. Mol. Plant Microbe Interact. 16, 827-834. doi: 10.1094/MPMI.2003.16.9.827

Gonzalez, J. E., and Marketon, M. M. (2003). Quorum sensing in nitrogen-fixing rhizobia. Microbiol. Mol. Biol. Rev. 67, 574-592. doi: 10.1128/MMBR.67.4.574592.2003

Gonzalez, J. F., Myers, M. P., and Venturi, V. (2013). The interkingdom solo OryR regulator of Xanthomonas oryzae is important for motility. Mol. Plant Pathol. 14, 211-221. doi: 10.1111/j.1364-3703.2012.00843.x

Gonzalez, J. F., and Venturi, V. (2013). A novel widespread interkingdom signaling circuit. Trends Plant. Sci. 18, 167-174. doi: 10.1016/j.tplants.2012.09.007

Keshavan, N. D., Chowdhary, P. K., Haines, D. C., and Gonzalez, J. E. (2005). LCanavanine made by Medicago sativa interferes with quorum sensing in Sinorhizobium meliloti. J. Bacteriol. 187, 8427-8436. doi: 10.1128/JB.187.24.84278436.2005

Lequette, Y., Lee, J. H., Ledgham, F., Lazdunski, A., and Greenberg, E. P. (2006). A distinct QscR regulon in the Pseudomonas aeruginosa quorum-sensing circuit. J. Bacteriol. 188, 3365-3370. doi: 10.1128/JB.188.9.3365-3370.2006

Mae, A., Montesano, M., Koiv, V., and Palva, E. T. (2001). Transgenic plants producing the bacterial pheromone $\mathrm{N}$-acyl-homoserine lactone exhibit enhanced resistance to the bacterial phytopathogen Erwinia carotovora. Mol. Plant Microbe Interact. 14, 1035-1042. doi: 10.1094/MPMI.2001.14.9.1035

Manefield, M., Rasmussen, T. B., Henzter, M., Andersen, J. B., Steinberg, P., Kjelleberg, S., et al. (2002). Halogenated furanones inhibit quorum sensing through accelerated LuxR turnover. Microbiology 148, 1119-1127.

Mathesius, U., Mulders, S., Gao, M., Teplitski, M., Caetano-Anolles, G., Rolfe, B. G., et al. (2003). Extensive and specific responses of a eukaryote to bacterial quorum-sensing signals. Proc. Natl. Acad. Sci. U.S.A. 100, 1444-1449. doi: 10.1073/pnas.262672599

Michael, B., Smith, J. N., Swift, S., Heffron, F., and Ahmer, B. M. (2001). SdiA of Salmonella enterica is a LuxR homolog that detects mixed microbial communities. J. Bacteriol. 183, 5733-5742. doi: 10.1128/JB.183.19.5733-5742.2001

Patankar, A. V., and Gonzalez, J. E. (2009). An orphan LuxR homolog of Sinorhizobium meliloti affects stress adaptation and competition for nodulation. Appl. Environ. Microbiol. 75, 946-955. doi: 10.1128/AEM.01692-08
Schenk, S. T., Stein, E., Kogel, K. H., and Schikora, A. (2012). Arabidopsis growth and defense are modulated by bacterial quorum sensing molecules. Plant Signal. Behav. 7, 178-181. doi: 10.4161/psb.18789

Schikora, A., Schenk, S. T., Stein, E., Molitor, A., Zuccaro, A., and Kogel, K. H. (2011). N-acyl-homoserine lactone confers resistance toward biotrophic and hemibiotrophic pathogens via altered activation of AtMPK6. Plant Physiol. 157, 1407-1418. doi: 10.1104/pp.111.180604

Schuhegger, R., Ihring, A., Gantner, S., Bahnweg, G., Knappe, C., Vogg, G., et al. (2006). Induction of systemic resistance in tomato by N-acyl-L-homoserine lactone-producing rhizosphere bacteria. Plant Cell Environ. 29, 909-918. doi: 10.1111/j.1365-3040.2005.01471.x

Shadel, G. S., Young, R., and Baldwin, T. O. (1990). Use of regulated cell lysis in a lethal genetic selection in Escherichia coli: identification of the autoinducerbinding region of the LuxR protein from Vibrio fischeri ATCC 7744. J. Bacteriol. 172, 3980-3987.

Slock, J., Vanriet, D., Kolibachuk, D., and Greenberg, E. P. (1990). Critical regions of the Vibrio fischeri LuxR protein defined by mutational analysis. J. Bacteriol. 172, 3974-3979.

Stevens, A. M., and Greenberg, E. P. (1997). Quorum sensing in Vibrio fischeri: essential elements for activation of the luminescence genes. J. Bacteriol. 179, $557-562$.

Subramoni, S., Gonzalez, J. F., Johnson, A., Pechy-Tarr, M., Rochat, L., Paulsen, I., et al. (2011). Bacterial subfamily of LuxR regulators that respond to plant compounds. Appl. Environ. Microbiol. 77, 4579-4588. doi: 10.1128/AEM.0018311

Subramoni, S., and Venturi, V. (2009). LuxR-family 'solos': bachelor sensors/regulators of signalling molecules. Microbiology 155, 1377-1385. doi: 10.1099/mic.0.026849-0

Teplitski, M., Chen, H., Rajamani, S., Gao, M., Merighi, M., Sayre, R. T., et al. (2004). Chlamydomonas reinhardtii secretes compounds that mimic bacterial signals and interfere with quorum sensing regulation in bacteria. Plant Physiol. 134, 137-146. doi: 10.1104/pp.103.029918

Teplitski, M., Robinson, J. B., and Bauer, W. D. (2000). Plants secrete substances that mimic bacterial $\mathrm{N}$-acyl homoserine lactone signal activities and affect population density-dependent behaviors in associated bacteria. Mol. Plant Microbe Interact. 13, 637-648. doi: 10.1094/MPMI.2000.13.6.637

Toth, I. K., Newton, J. A., Hyman, L. J., Lees, A. K., Daykin, M., Ortori, C., et al. (2004). Potato plants genetically modified to produce $\mathrm{N}$-acylhomoserine lactones increase susceptibility to soft rot erwiniae. Mol. Plant Microbe Interact. 17, 880887. doi: 10.1094/MPMI.2004.17.8.880

Venturi, V., and Fuqua, C. (2013). Chemical signaling between plants and plant pathogenic bacteria. Annu. Rev. Phytopathol. 51, 17-37. doi: 10.1146/annurevphyto-082712-102239

Von Bodman, S. B., Bauer, W. D., and Coplin, D. L. (2003). Quorum sensing in plant-pathogenic bacteria. Annu. Rev. Phytopathol. 41, 455-482. doi: 10.1146/annurev.phyto.41.052002.095652

von Rad, U., Klein, I., Dobrev, P. I., Kottova, J., Zazimalova, E., Fekete, A., et al. (2008). Response of Arabidopsis thaliana to N-hexanoyl-DL: -homoserinelactone, a bacterial quorum sensing molecule produced in the rhizosphere. Planta 229, 73-85. doi: 10.1007/s00425-008-0811-4

Whitehead, N. A., Barnard, A. M., Slater, H., Simpson, N. J., and Salmond, G. P. (2001). Quorum-sensing in Gram-negative bacteria. FEMS Microbiol. Rev. 25, 365-404. doi: 10.1111/j.1574-6976.2001.tb00583.x

Yao, Y., Martinez-Yamout, M. A., Dickerson, T. J., Brogan, A. P., Wright, P. E., and Dyson, H. J. (2006). Structure of the Escherichia coli quorum sensing protein SdiA: activation of the folding switch by acyl homoserine lactones. J. Mol. Biol. 355, 262-273. doi: 10.1016/j.jmb.2005.10.041

You, Y. S., Marella, H., Zentella, R., Zhou, Y., Ulmasov, T., Ho, T. H., et al. (2006). Use of bacterial quorum-sensing components to regulate gene expression in plants. Plant Physiol. 140, 1205-1212. doi: 10.1104/pp.105.074666

Zhang, L., Jia, Y., Wang, L., and Fang, R. (2007). A proline iminopeptidase gene upregulated in planta by a LuxR homologue is essential for pathogenicity of Xanthomonas campestris pv. campestris. Mol. Microbiol. 65, 121-136. doi: 10.1111/j.1365-2958.2007.05775.x

Zhang, R. G., Pappas, K. M., Brace, J. L., Miller, P. C., Oulmassov, T., Molyneaux, J. M., et al. (2002). Structure of a bacterial quorum-sensing transcription factor complexed with pheromone and DNA. Nature 417, 971-974. doi: 10.1038 /nature00833 
Conflict of Interest Statement: The authors declare that the research was conducted in the absence of any commercial or financial relationships that could be construed as a potential conflict of interest.

Received: 29 May 2013; accepted: 19 October 2013; published online: 12 November 2013.

Citation: Patel HK, Suárez-Moreno ZR, Degrassi G, Subramoni S, González JF and Venturi V (2013) Bacterial LuxR solos have evolved to respond to different molecules including signals from plants. Front. Plant Sci. 4:447. doi: 10.3389/fpls.2013.00447
This article was submitted to Plant-Microbe Interaction, a section of the journal Frontiers in Plant Science.

Copyright (c) 2013 Patel, Suárez-Moreno, Degrassi, Subramoni, González and Venturi. This is an open-access article distributed under the terms of the Creative Commons Attribution License (CC BY). The use, distribution or reproduction in other forums is permitted, provided the original author(s) or licensor are credited and that the original publication in this journal is cited, in accordance with accepted academic practice. No use, distribution or reproduction is permitted which does not comply with these terms. 